\title{
REDUCTION OF SCRAP INDICATORS THROUGH QUALITY TOOLS: A CASE STUDY OF A TWO-WHEEL SEGMENT METALWORKING INDUSTRY
}

\author{
Alexandre da Silva Freire ${ }^{1}$, Luciberg Soares Bobot ${ }^{2}$, Raquel Alves do Nascimento Corrêa ${ }^{3}$ \\ Marcelo DuarteVieira ${ }^{4}$, Anderson de Oliveira Castro ${ }^{5}$, Anderson Caldas de Oliveira ${ }^{6}$
}

\author{
1,2,5,6 Universidade do Norte - Uninorte Av. Leonardo Malcher, 715 Manaus. \\ ${ }^{3,4}$ Departamento de Engenharia Indústrial, Universidade Uminho, Campus de Azurém, 4800-058 Guimarâes, Portugal. \\ Email: alexandre.asv4@gmail.com, lucibergsb@gmail.com, rakel.an@hotmail.com, marcelo.duarteep@gmail.com,
} anderson.castro@uninorte.com.br

Received: May 24th, 2019

Accepted: June $25^{\text {th }}, 2019$

Published: September $30^{\text {th }}$, 2019

Copyright @ 2016 by authors and Institute of Technology Galileo of Amazon (ITEGAM). This work is licensed under the Creative Commons Attribution International License (CC BY 4.0). https://creativecommons.org/lice nses/by/4.0/

\section{ABSTRACT}

The present study aims to show that the analysis and problem solving using the quality tools in a machining sector in a metallurgical company located in Manaus Industrial Pole is effective in order to maintain or improve the quality of products. Clarification and reduction of the real causes of problems are a permanent attention and an important mechanism for maintaining customer focus, ensured through the use of quality tools. In this case study, the tools are used to investigate root causes at all stages of the organization's domain and address nonconformities through corrective action and preventive action, clearly indicating the importance and effectiveness of results through their use systematized.

Keywords: Quality tools, High scrap rate, Corrective action, Preventive action.

\section{REDUÇÃO DE INDICADORES DE SUCATA POR MEIO DE FERRAMENTAS DA QUALIDADE: UM ESTUDO DE CASO DE UMA INDÚSTRIA METAL MECÂNICO, SEGMENTO DUAS RODAS}

\section{RESUMO}

O presente estudo tem como objetivo mostrar que a análise e solução de problemas utilizando as Ferramentas da Qualidade em um setor de usinagem em uma empresa do ramo metalúrgico lotada no Pólo Industrial de Manaus, é eficaz, de forma a manter ou melhorar a qualidade dos produtos entregues, e, por conseguinte, manter ou aumentar o nível de satisfação de seus clientes. $\mathrm{O}$ esclarecimento e a redução das reais causas dos problemas são uma atenção permanente e um importante mecanismo de manutenção do foco no cliente, garantido através do uso das Ferramentas da Qualidade. Nesse estudo de caso, as ferramentas são utilizadas para investigação das causas raízes em todas as etapas de domínio da organização e o tratamento das nãoconformidades através de ação corretiva e ação preventiva, indicando claramente a importância e a eficácia dos resultados através do seu uso sistematizado.

Keywords: Ferramentas da qualidade. Índice de sucata elevado. Ação corretiva. Ação preventiva.

\section{INTRODUÇÃO}

Com a crescente globalização econômica, as estratégias para a competitividade exigem das empresas e do empresariado, uma verdadeira mudança cultural de uma forma abrupta e rápida, porém até o início da década de 1990, o mercado nacional era fechado. As empresas tinham como foco o ganho proporcionado pela ciranda financeira. A partir da abertura da economia brasileira, no início dos anos de 1990, as empresas se depararam com uma nova realidade: a falta de competitividade entre as indústrias 
nacionais, ora em qualidade ora em custos. E isso as obrigou a mudar o foco.

Em função das novas condições exigidas pelo cenário nacional, caracterizada por bons preços, menor prazo de entrega, exigência de qualidade, maior diversificação dos produtos e outros; em Manaus não foi diferente. Pelo contexto do próprio Pólo Industrial, que era muito focado na importação de produto, logo foi bruscamente atingido tendo assim que se adaptar a novo ambiente competitivo, novas mudanças de sistemas de produção e a introdução de novas tecnologias de informações exercem uma pressão na direção de uma organização diferenciada, que responda de forma rápida aos apelos e necessidades do ambiente externo, em busca de aumentos de produtividade e redução de custos na gestão de seus negócios.

Considerando essa avaliação, pretendeu-se com essa pesquisa estudar o sistema da qualidade de uma empresa do PIM, visando a utilização de Ferramentas da Qualidade e método para análise e solução de problemas a partir da área do controle da qualidade da empresa no setor de usinagem no processo de fabricação do produto eixo de transmissão para motos. A presente empresa enfrenta alto índice de não-conformidade no produto eixo de transmissão para motos, sendo a maior ocorrência de reclamações na empresa.

\section{DESENVOLVIMENTO}

Atualmente o diálogo com o cliente permite que a empresa busque a excelência no atendimento. Mas, quando se trata de competitividade, é preciso ir além: prever suas necessidades e superar expectativas, até mesmo, porque a gestão pela qualidade assegura satisfação não só do cliente final, mas de todos aqueles que fazem parte dos diversos processos da empresa: clientes externos e internos; diretos e indiretos; parceiros e colaboradores em todos os níveis. E como colaboradora do setor de Engenharia de Processo da empresa estudada, foi observado que há uma necessidade de melhoria no setor de usinagem de eixo, pois conforme dados da produção, o índice de sucata encontrava-se elevado. Sabendo também que a organização possui o Sistema de Gestão da Qualidade implantado, passando a demonstrar para o seu cliente, total capacidade de fornecer produtos que atendam aos requisitos do cliente, aumentando a satisfação do mesmo por meio da melhoria contínua do sistema. Buscou-se com a aplicação das ferramentas da qualidade reduzir o índice de sucata do setor.

Figura 1: Percentual de Sucata mensal do setor de Usinagem.

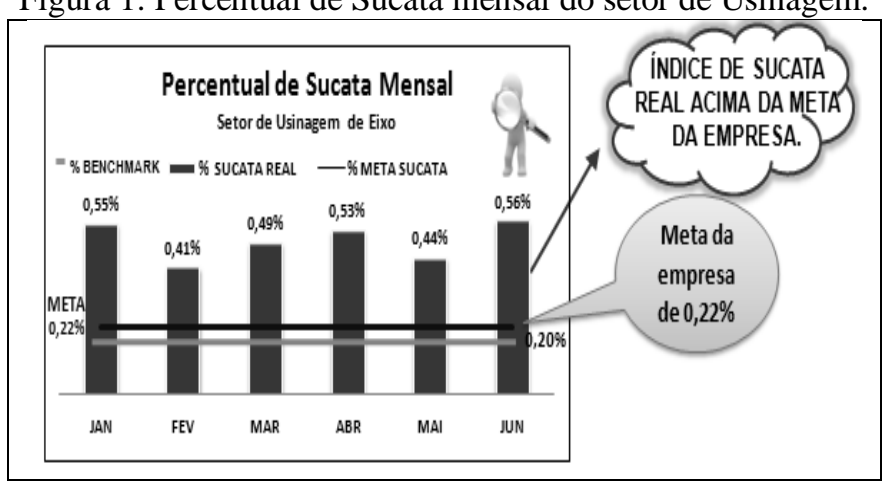

Fonte: Autores, (2014).

Durante o período de janeiro à junho, o produto eixo de transmissão apresentou um número elevado de sucata, cuja quantidade equivale ao índice mensal de sucata acima da meta (ver figura 1).

A meta da empresa é de $0,22 \%$ em relação à quantidade de peças produzidas. O Benchmark com outras empresas do mesmo segmento é de $0,20 \%$. A empresa mantinha um índice de mínimo de $0,41 \%$ e máximo de $0,56 \%$ de sucata, gerando um elevado custo com desperdício. Em uma análise, foi constatado que apenas atingindo a meta, a indústria reduziria mais de $50 \%$ da sucata mensal e com redução média de $0,27 \%$ de sucata, seria possível o atendimento da meta da empresa. Isso representa uma redução com desperdício de sucata de aproximadamente $\mathrm{R} \$$ 50.000/ano.

Figura 2: Gráfico de Sucata mensal do setor de Usinagem.

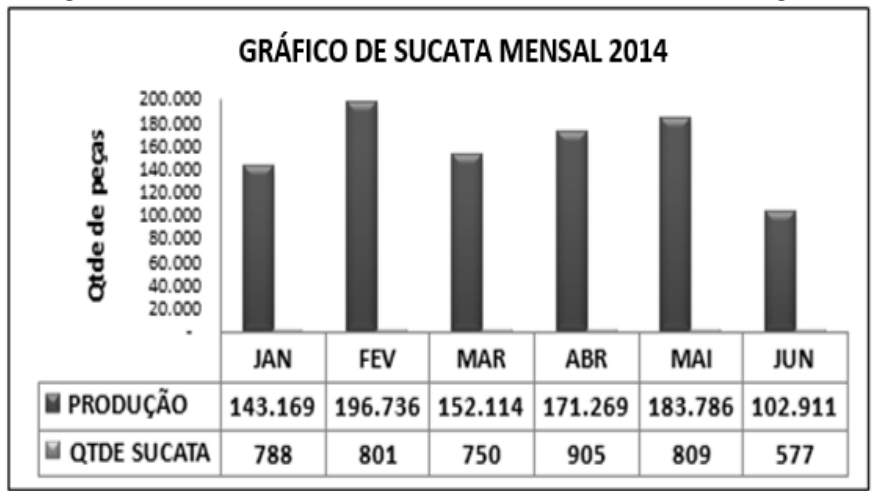

Fonte: Autores, (2014).

Na figura 2, é possível visualizar que a empresa apresentou um total de 4.630 peças de sucata no primeiro semestre de 2014, isto significa aproximadamente 770 peças por mês. Considerando a meta do índice da empresa de $0,22 \%$ em média a quantidade de sucata seria de 348 peças e não de 770 peças como mostra os dados acima.

Essa quantidade redobrada de sucata é resultante das falhas internas que são os custos que a empresa paga pela má qualidade observada antes que o cliente se dê conta. Quando a peça considerada como sucata chega ao cliente, é considerado como falhas externas, que são os custos que a empresa paga pela má qualidade que chega até o cliente final, acarretando substituição de produtos, serviços ou compensações por perdas sofridas pelo usuário. Essas falhas ocasionam grandes perdas em custos intangíveis, como destruição da imagem e credibilidade da empresa. Quanto mais tarde erros forem detectados, maiores serão os custos envolvidos para corrigi-los, além de ocasionar perdas que muitas vezes são irreversíveis.

\section{Ações para Melhoria}

- Específico: Reduzir índice de sucata em $40 \%$ do eixo de transmissão no setor de usinagem.

- Amplo: Espera-se contribuir com o aumento da lucratividade da empresa, recuperar o valor gasto com desperdício; reduzir o tempo de preparação nas máquinas e enfatizar a importância do trabalho para motivar os colaboradores a participar de projeto com temas de melhorias nos processos.

A construção deste trabalho foi baseada em um procedimento interno da empresa, onde foram regulamentadas as seguidas as etapas abaixo:

Participar de um projeto de melhorias;

Definir o grupo de trabalho;

Definir atividades e o período para a realização do trabalho;

Análise da situação: O estudo de caso teve como auxílio na análise consulta a indicadores fornecidos pela própria empresa. Com o aprofundamento dos conceitos, melhor entendimento da realidade e necessidades da empresa e objetivando o enriquecimento dos resultados. A aplicação das ferramentas da qualidade foi de grande valia para identificar as causas e contribuir 
para a proposta de ações na redução do índice de sucata do eixo de transmissão no setor de usinagem;

Melhorias Propostas e ganhos esperados com a implantação da melhoria: O grupo consolidou-se em ações que não causasse impacto financeiro para a empresa, visto que nos últimos meses a empresa já havia um histórico elevado com desperdício devido o problema em questão.

Implantação e resultados obtidos: Nesta etapa é grande importância o acompanhamento das ações de forma sistêmica. O processo depois de implantado deve ser padronizado e documentado de forma que evite a reincidência da não conformidade. Nesta fase, o grupo conseguiu avaliar o ganho evitando o desperdício com a sucata no setor de usinagem.

Melhorias Propostas e ganhos esperados com a implantação da melhoria: O grupo consolidou-se em ações que não causasse impacto financeiro para a empresa, visto que nos últimos meses a empresa já havia um histórico elevado com desperdício devido o problema em questão.

Implantação e resultados obtidos: Nesta etapa é grande importância o acompanhamento das ações de forma sistêmica. $\mathrm{O}$ processo depois de implantado deve ser padronizado e documentado de forma que evite a reincidência da não conformidade. Nesta fase, o grupo conseguiu avaliar o ganho evitando o desperdício com a sucata no setor de usinagem.

\subsection{Análise da Situação Atual}

A empresa estudada está localizada no Pólo Industrial de Manaus e foi construída em 2002, contando atualmente com aproximadamente 570 colaboradores. Pertencente ao tradicional grupo japonês, a empresa fabrica conjunto eixo de transmissão, virabrequins e bielas para motores de veículos de duas rodas.

A empresa dispõe de tecnologia de ponta para testar seus produtos, todas voltadas para testar a funcionalidade dos produtos, visando à satisfação e o conforto dos seus clientes e usuários em geral.

A mão-de-obra recebe treinamentos diversos, apropriados e voltados para cada seção desde o mais simples, como matemática básica, metrologia, ao mais sofisticado e tecnológico como estágio na matriz (Japão) pelo período de 06 meses.

\subsection{Caracterização da Área estudada}

Com sua matriz no Japão, a empresa mantém operações em diversos países. No Brasil, iniciaram-se suas atividades a partir do convite de quem é hoje seu maior cliente. Atualmente é líder mundial no setor industrial em que atua e é detentora de tecnologia de ponta desenvolvida em seus próprios centros de P\&D.

Sua planta no Pólo Industrial de Manaus é dividida em: Administração, PCP, Qualidade, R.H, T.I, Compras, Comercial, Financeiro, Engenharia, Manutenção, Expedição, Almoxarifado, Recebimento, Fiscal, Refeitório, Ambulatório, Sesmet e a Área Produtiva da Fábrica, onde existem os setores de Usinagem, Retífica, Tratamento Térmico, Brunimento, Montagem, uma área destinada para o estacionamento de carretas, depósito de efluentes e produtos químicos, uma área específica para a agência do Banco Brasil e uma pracinha para descanso. O setor onde será realizado o estudo será o de Usinagem, mais especificamente o setor de Usinagem de Eixo de Transmissão.

\subsection{Situação Atual}

O setor da empresa que analisamos é o setor de usinagem de eixo. Este possui várias máquinas produzindo vários modelos, sendo que algumas delas são destinadas a um único modelo, devido ao seu grande volume de produção.
Figura 3: Modelo de Eixo de Transmissão.

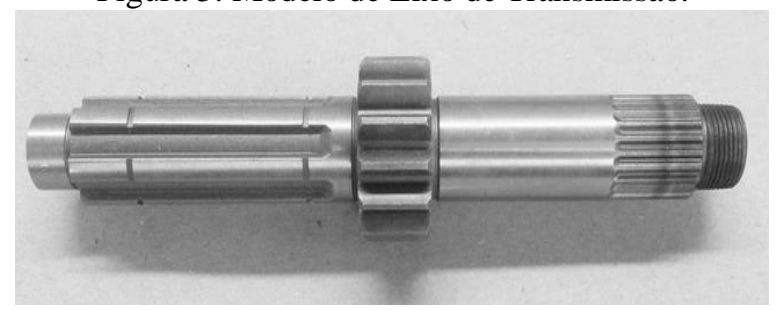

Fonte: Autores, (2014).

A figura 3 se trata de um dos modelos de eixo produzidos no setor. Cada setor na fabrica recebeu o nome do que se produz. Neste caso Setor de Usinagem de eixo por produzir somente eixos de transmissão primários e secundários.

Quando se trata de eixo de transmissão o fluxo é igual, sendo que a diferença entre os produtos é sempre o dimensional descrito em desenhos técnicos.

Figura 4: Fluxo Geral do Processo.

\section{FLUXO DO GERAL DO PROCESSO}

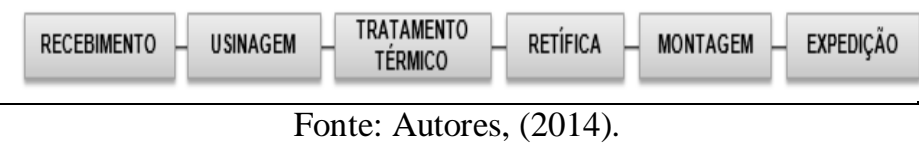

Na figura acima, é demonstrado o fluxo geral de todos os eixos de transmissão. Cada etapa do fluxo significa um setor da empresa até chegar à expedição, que é setor responsável em entregar as peças ao cliente.

Figura 5: Fluxo Detalhado do Processo de Usinagem de Eixo. FLUXO DETALHADO DO PROCESSO DE USINAGEM DE EIXO

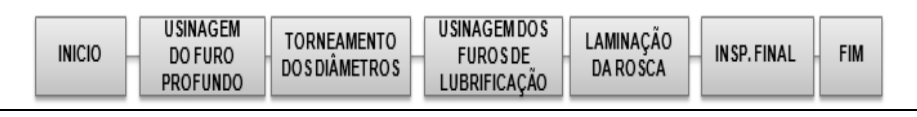

Fonte: Autores, (2014).

Nesta outra figura, é demonstrado o fluxo detalhado somente do processo de usinagem de eixos, que é o setor analisado. Conforme descrito acima, todos os eixos passam pelos mesmos processos, porém com diferenças dimensionais, seja ele nos diâmetros, comprimentos, alturas, quantidade de furos e especificação da rosca.

A pesquisa neste setor delimitou-se no período de janeiro à junho de 2014, que de acordo com dados dos relatórios da própria empresa, foram extraídos os números para se descobrir quais eram os problemas mais reincidentes do setor.

Figura 6: Gráfico de Pareto do Processo de Usinagem de Eixo. GRÁFICO DE PARETO

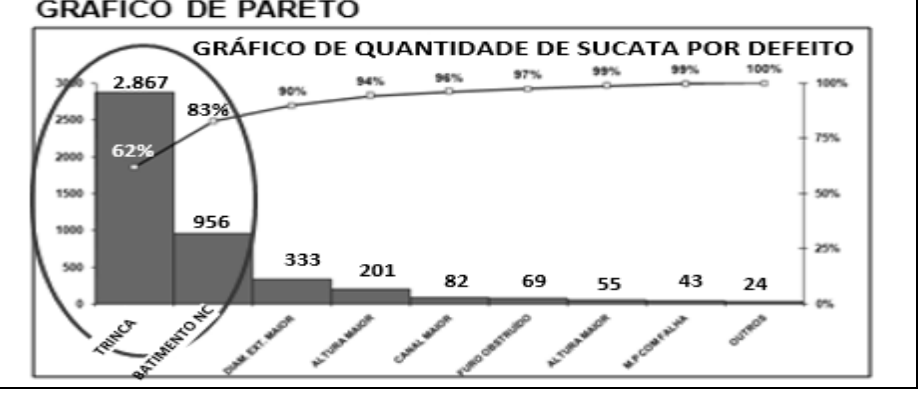

Fonte: Autores, (2014).

Conforme é possível visualizar no Gráfico de Pareto acima, $83 \%$ da quantidade de sucata são referentes a problemas de TRINCA E BATIMENTO NC (Não conforme) e em virtude desse 
alto número de peças defeituosas buscou-se investigar as causas que levavam a essas não conformidades.

Nesta etapa da análise, para se analisar as causas raízes do problema foram utilizadas as ferramentas da qualidade: Diagrama de Causa e Efeito - Ishikawa e Matriz GUT.

É importante salientar que o uso das ferramentas de qualidade é justamente para não tomar decisões precipitadas ao identificar um problema, pois a análise errada acaba prejudicando a organização, ou ainda desperdiçando recursos tentando resolver um problema errado, isto é, não necessário no momento.

Figura 7: Diagrama de Causa e Efeito do setor de Usinagem.

Diagrama de Causa e Efeito - Ishikawa

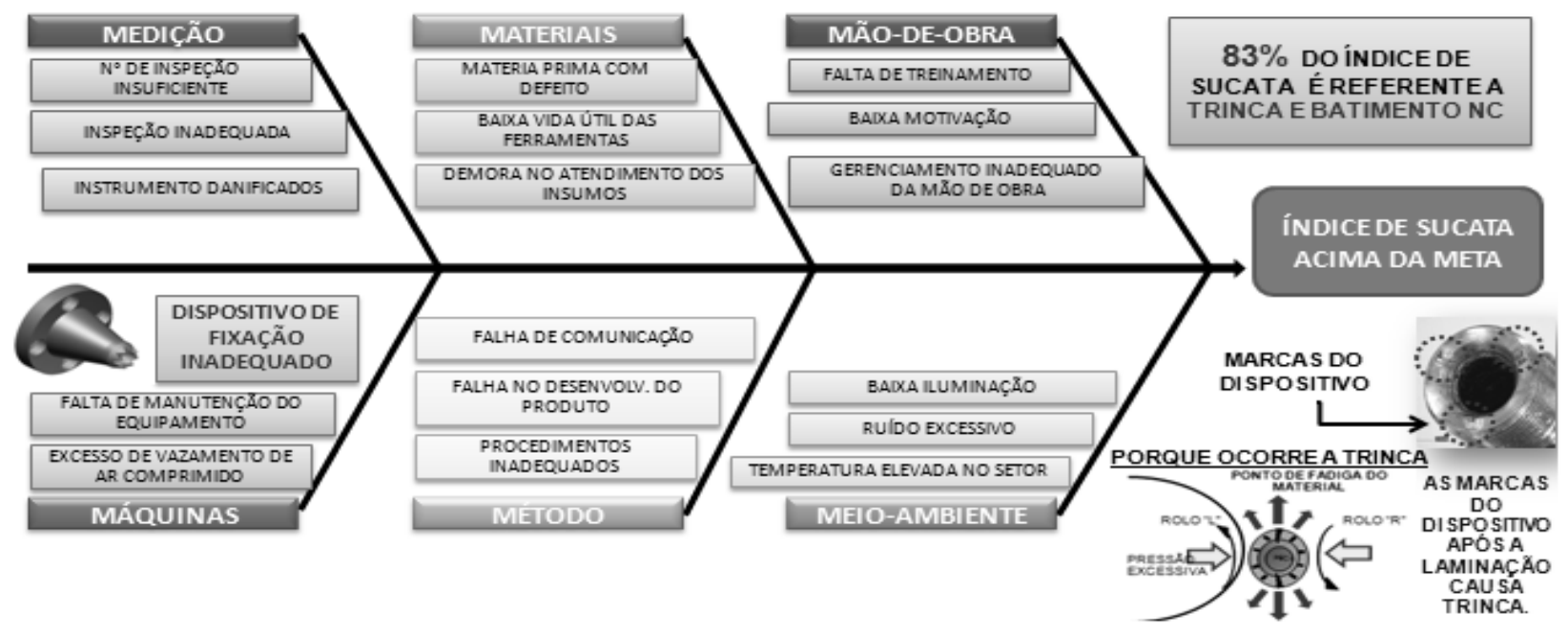

Fonte: Autores, (2014).

No Diagrama de Causa e efeito como o próprio nome já diz, trabalhamos o problema relacionando o defeito com suas causas. Utilizamos nessa ferramenta os seguintes itens: medição, materiais, mão de obra, máquinas, método e meio ambiente. Em cada ramificação, foram colocadas as possíveis causas.

Nesta análise, constatamos que o índice de sucata acima da meta era associado ao dispositivo de fixação da peça, que era utilizado no processo de usinagem. O dispositivo estava sendo inadequado para o processo e ocasionava as não conformidades.

A mistura de problemas por si só gerou confusão, e acabou dificultando a visão na identificação dos problemas prioritários e na sua relevância. Com isso, para consolidar a análise do problema, outra ferramenta foi utilizada, a Matriz GUT. Com o uso desta ferramenta, extraímos informações importantes para o trabalho. Trabalhamos com Gravidade, Urgência e Tendência, separamos os problemas que tinha causa própria e somente após isso, soubemos qual era a nossa prioridade na solução dos problemas identificados: Dispositivo de fixação inadequado, o que confirmou a nossa análise.

\subsection{Matriz GUT}

Figura 8: Matriz GUT do setor de Usinagem.

\begin{tabular}{|c|c|c|c|c|c|}
\hline PROBLEMAS & $\begin{array}{l}\text { GRAVIDADE } \\
\text { (G) }\end{array}$ & $\begin{array}{l}\text { URGÊNCIA } \\
\text { (U) }\end{array}$ & $\begin{array}{l}\text { TENDÊNCIA } \\
\text { (T) }\end{array}$ & $\begin{array}{l}\text { PONTUAÇÃO } \\
(G \times \cup \times T)\end{array}$ & PRIORIZAÇÃo \\
\hline DISPOSITIVO DE FIXAÇÃO INADEQUADO & 5 & 5 & 5 & 125 & 12 \\
\hline N² DE INSPEÇÃO INSUFICIENTE & 4 & 5 & 5 & 100 & 29 \\
\hline FALTA DE TREINAMENTO & 4 & 5 & 4 & so & 39 \\
\hline FALHA DE COMUNICAÇño & 4 & 5 & 3 & 60 & 49 \\
\hline MATERIA PRIMA COM DEFEITO & 3 & 4 & 2 & 24 & 59 \\
\hline BAIXA ILUMINAÇÃO & 3 & 2 & 2 & 12 & 69 \\
\hline INSPEÇÃO INADEQUADA & 3 & 2 & 2 & 12 & 79 \\
\hline INSTRUMENTO DANIFICADOS & 3 & 2 & 2 & 12 & 79 \\
\hline BAIXA VIDA ÚTIL DAS FERRAMENTAS & 3 & 2 & 2 & 12 & 79 \\
\hline DEMORA NO ATENDIMENTO DOS INSUMOS & 3 & 2 & 2 & 12 & 79 \\
\hline BAIXA MOTNAÇÃO & 3 & 2 & 2 & 12 & 79 \\
\hline GERENCIAMENTO INADEQUADO DA MÃO DE OBRA & 3 & 2 & 2 & 12 & 79 \\
\hline FALTA DE MANUTENÇãO DO EQUIPAMENTO & 3 & 2 & 2 & 12 & 79 \\
\hline EXCESSO DE VAZAMIENTO DEAR COMPRIMIDO & 3 & 2 & 2 & 12 & 79 \\
\hline FALHA NO DESENVOLV. DO PRODUTO & 3 & 2 & 2 & 12 & 79 \\
\hline PROCEDIMENTOS INADEQUADOS & 3 & 2 & 2 & 12 & 79 \\
\hline RUÍDO EXCESSIVO & 3 & 2 & 2 & 12 & 79 \\
\hline TEMPERATURA ELEVADA NO SETOR & 3 & 2 & 2 & 12 & 79 \\
\hline
\end{tabular}

Fonte: Autores, (2014). 
Conforme é possível visualizar na nossa matriz GUT (ver figura 8), o dispositivo de fixação se tornou nossa prioridade. Isso porque o problema de TRINCA era um problema muito grave, com risco de quebra após a montagem da peça no motor da moto, gerando risco à vida do usuário com o travamento do motor. $\mathrm{O}$ problema é tão sério que se pode levar à um Recall, que é o recolhimento do produto no mercado. Isso porque nenhum fabricante pode produzir e colocar algo no mercado de consumo, produtos que apresente alto grau de risco à saúde ou segurança das pessoas.

Figura 9: Causa do Problema de Trinca e Batimento NC.

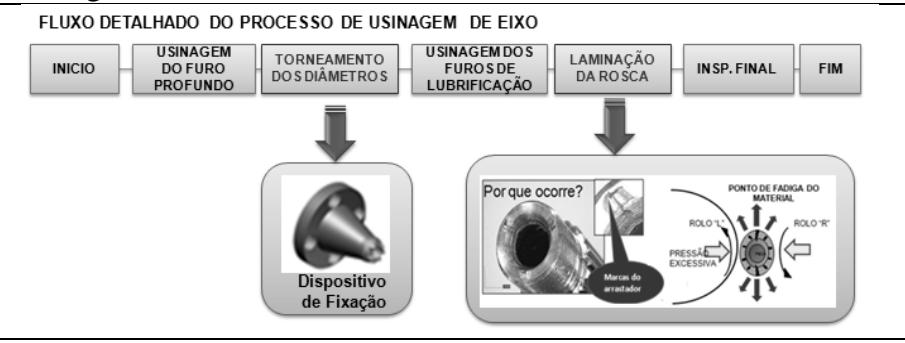

Fonte: Do próprio autor, 2014.

Na figura 9, entendemos como se originou o problema da trinca e do Batimento NC (Não conforme). O fluxo mostra que no processo de TORNEAMENTO DOS DIÂMETROS o dispositivo utilizado para fixação da peça durante a usinagem possuía pontas de arrastes, que além de deixar marcas, não proporcionava uma fixação uniforme na peça. Durante o processo de LAMINAÇÃO DA ROSCA (processo de rosca próximo à face), a peça trincava com esforços dos rolos L (Left) e R (Right), pois as marcas na face da peça eram profundas. A pressão de ar das máquinas da empresa não era padronizada, portanto as máquinas trabalhavam ora em uma pressão de fixação da peça regular, ora desregular, momento esse causando a não conformidade na peça.

\section{Referências Teóricas}

2.1 Utilização de ferramentas na composição do projeto de melhoria

A utilização de ferramentas da qualidade no projeto de melhoria auxiliou o trabalho a ter uma visão sistêmica do inicio ao fim do projeto. Um projeto deve agregar valores de melhoria em um processo, como resultados financeiros, com ganhos de produtividade e melhoria de desempenho, então seu gerenciamento deve ser realizado de maneira que todas as etapas sejam perfeitamente monitoradas para que o mesmo tenha êxito.

A proposta do trabalho é demonstrar que um projeto gerenciado por ferramentas da qualidade é de fundamental importância para seu sucesso, tem o objetivo de melhorar os processos de rotina, tem inicio e fim determinado, deve ter um prazo definido com todas as ações requerentes, "meios" para se atingir o "fim".

Para Deming em [1], "a qualidade deve ter como objetivo as necessidades do usuário, presentes e futuras".

As empresas precisam de qualidade, valor agregado, serviço, inovação, flexibilidade, agilidade e velocidade de forma cada vez mais crítica. Para tanto, são necessárias melhorias contínuas, investimentos em treinamento de pessoal, e alternativas que façam com que os clientes percebam que a empresa é confiável e oferece vantagens para ele. As empresas tendem a se diferenciar pelo que elas sabem e pela forma como conseguem usar esse conhecimento [2].

\subsubsection{Fluxograma}

Figura 10: Fluxograma do Processo de Estamparia.

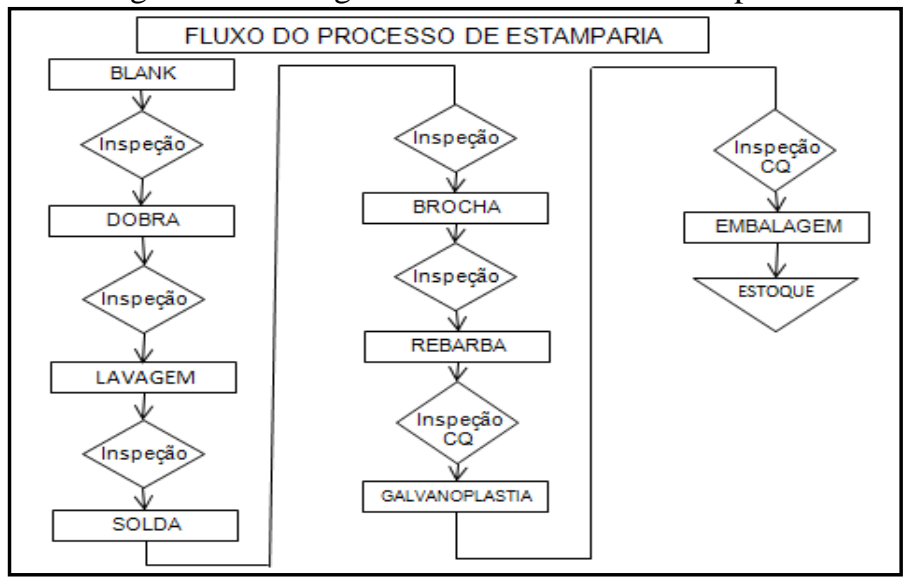

Fonte: [3].

No trabalho representamos o processo de usinagem através do fluxograma, que é uma ferramenta visual que possibilitou maior facilidade na localização de ações específicas. Na figura 10, exemplificamos o fluxograma em um modelo simples de processo de estamparia, através desta representação gráfica é possível compreender de forma rápida e fácil a transição dos processo como aconteceu no fluxograma do nosso processo.

[4] diz que o fluxograma é utilizado no gerenciamento com a finalidade de garantir a qualidade e aumentar a produtividade. Representa ainda o início da padronização, ou seja, a garantia da qualidade.

\subsubsection{Gráfico e/ou Diagrama de Pareto}

Figura 11: Gráfico de Pareto.

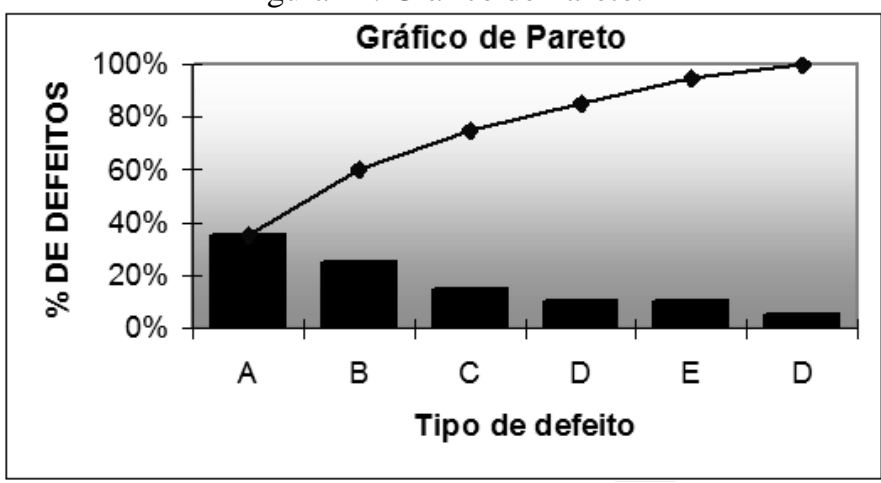

Fonte: [3].

Diagrama de Pareto é um gráfico de barras que ordena as frequências das ocorrências, da maior para a menor, permitindo a priorização dos problemas. Mostra ainda a curva de percentagens acumuladas (ver figura 11). Sua maior utilidade é a de permitir uma fácil visualização e identificação das causas ou problemas mais importantes, possibilitando a concentração de esforços sobre os mesmos.

O diagrama de Pareto é constituído a partir de uma tabela mais completa, onde as freqüências são multiplicadas pelo peso correspondente a cada elemento. O produto desta multiplicação é que mostrará os elementos mais importantes em termos de prioridade para o estudo [5]. Ou seja, se os sistemas ou causas de produtos defeituosos ou de algum outro "efeito" são identificados e registrados, é possível determinar que porcentagem pode ser atribuída a cada uma das causas. O resultado provável é que a maior 
parte (tipicamente, 80\%) dos erros, perdas ou "efeitos" seja originada de poucas causas (tipicamente, 20\%) [1].

Neste estudo de caso, o gráfico de Pareto utilizado dispõe a informação de modo que se tornou possível a identificação dos principais problemas enfrentados pela empresa: Trinca e Batimento NC, que no cálculo de porcentagem, os dois juntos eram equivalentes à $83 \%$ da causa das não conformidades. Um número significativo em relação aos demais problemas apresentados pelo setor.

\subsubsection{Diagrama de causa e efeito - Ishikawa}

É uma ferramenta utilizada para apresentar a relação existente entre um resultado de um processo (efeito) e os fatores (causas) do processo que, por razões técnicas, possam afetar o resultado considerado [6].

Figura 12: Diagrama de Espinha de Peixe.

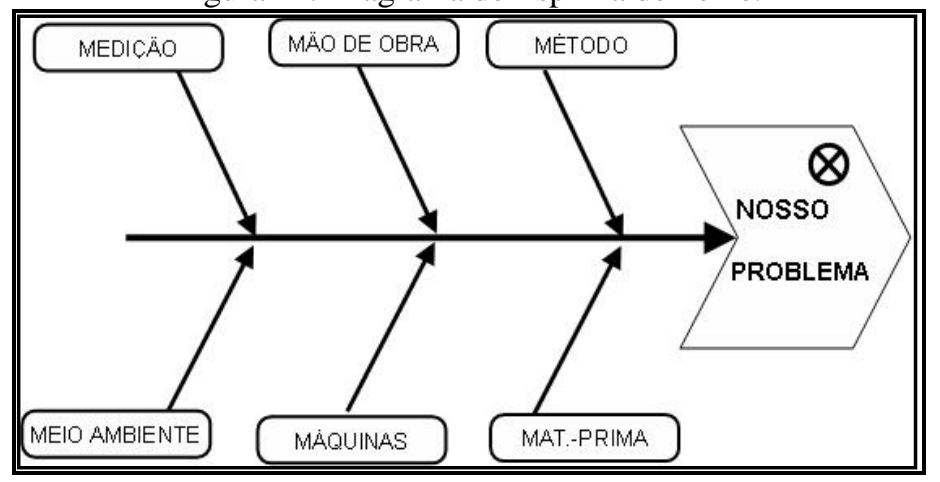

Fonte: [3].

Como a sua forma lembra o esqueleto de um peixe (ver figura 12), o diagrama também é conhecido como Diagrama de Espinha de Peixe. Uma terceira denominação para este diagrama é Diagrama de Ishikawa, em homenagem ao Professor Kaoru Ishikawa, que construiu o primeiro diagrama de causa e efeito para explicar a alguns engenheiros de uma indústria japonesa como vários fatores de um processo estavam inter-relacionados.

Para [5], é importante o grupo classificar a análise em quatro tipos, a saber:

- Máquinas: decorrentes de problemas de máquinas, equipamentos e instalações;

- Materiais: resultantes de problemas de materiais, matériasprimas, semi-acabados, materiais de consumo;

Métodos: decorrentes da metodologia de execução das atividades, tais como procedimentos, rotinas, normas, instruções;

- Mão-de-obra: resultantes das ações, comportamentos e competências dos empregados.

Terminada a classificação, as causas são registradas no diagrama no espaço reservado ao tipo de causa. Na extremidade direita do gráfico, é registrado o problema ou o "efeito" daquelas causas.

Para o levantamento das causas neste estudo foi realizada uma reunião conduzida por uma técnica conhecida como "brainstorming", que no próximo tópico falaremos mais a respeito. No "brainstorming" é aconselhável a participação do maior número possível de pessoas envolvidas com o processo. No nosso caso, a reunião teve um resultado muito importante para a construção de um diagrama completo, que não omitisse causas relevantes.

\subsubsection{Matriz GUT (Gravidade, Urgência e Tendência)}

GUT é uma ferramenta usada para definir prioridades dada as diversas alternativas de ação. Esta ferramenta responde racionalmente às questões:
O que devemos fazer primeiro?

Por onde devemos começar?

Para responder a tais questões a ferramenta GUT leva em consideração a: Gravidade, Urgência e Tendência do fenômeno.

Por GRAVIDADE devemos considerar a intensidade, profundidade dos danos que o problema pode causar se não se atuar sobre ele;

Por URGÊNCIA devemos considerar o tempo para a eclosão dos danos ou resultados indesejáveis se não se atuar sobre o problema;

Por TENDÊNCIA devemos considerar o desenvolvimento que o problema terá na ausência de ação.

A Matriz GUT foi aplicada neste trabalho, pois precisávamos priorizar ações dentro de um leque de alternativas que foram apontadas. O objetivo desta ferramenta é justamente ordenar a importância das ações pela sua GRAVIDADE, pela sua URGÊNCIA e pela sua TENDÊNCIA de forma racional, permitindo escolher a tomada de ação menos prejudicial.

Ao se saber que o tempo é um recurso escasso e que há inúmeras atividades a executar, deve-se perguntar: quais atividades devem ser executadas primeiro? Por quê? Essas são as respostas que a ferramenta dá.

GRAVIDADE: consideramos a intensidade ou profundidade dos danos que o problema pode causar se não se atuar sobre ele. Tais danos podem ser avaliados quantitativa ou qualitativamente.

URGÊNCIA: considera o tempo para a eclosão de danos ou resultados indesejáveis se não se atuar sobre o problema. O período de tempo também é considerado numa escala de 1 a 5:

TENDÊNCIA: considerar o desenvolvimento que o problema terá na ausência de ação. A tendência também é definida numa escala de 1 a 5 :

Essa ferramenta pode ser aplicada individualmente, mas o resultado é melhor quando um grupo de pessoas a executa, já que haverá um aprimoramento nos valores GUT que devem ser obtidos por consenso (consenso = Conformidade, acordo ou concordância de idéias, de opiniões). É útil para o planejamento de atividades que devem ser realizadas num determinado período. A ferramenta requer o uso de um formulário, como o modelo abaixo.

\subsubsection{W2H}

Figura 13: Quadro de 5W2H.

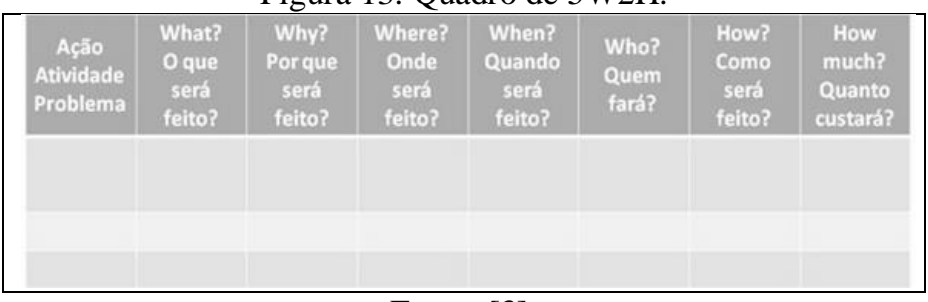

Fonte: [3].

O 5W2H (ver figura 13), basicamente, é um checklist de determinadas atividades que precisam ser desenvolvidas com o máximo de clareza possível por parte dos colaboradores da empresa. Ele funciona como um mapeamento destas atividades, onde ficará estabelecido o que será feito, quem fará o quê, em qual período de tempo, em qual área da empresa e todos os motivos pelos quais esta atividade deve ser feita. Em um segundo momento, deverá figurar nesta tabela como será feita esta atividade e quanto custará aos cofres da empresa tal processo.

O nome desta ferramenta foi assim estabelecido por juntar as primeiras letras dos nomes (em inglês) das diretrizes utilizadas neste processo. Abaixo você pode ver cada uma delas e o que elas representam: 
What - O que será feito (etapas)

Why - Por que será feito (justificativa)

Where - Onde será feito (local)

When - Quando será feito (tempo)

Who - Por quem será feito (responsabilidade)

How - Como será feito (método)

How much - Quanto custará fazer (custo)
3. Melhorias Realizadas

Este capítulo apresenta o plano de ação, que realizou as ações de melhoria provindas da análise documental e in loco, baseadas no método $5 \mathrm{~W} 2 \mathrm{H}$ como cita o referencial teórico.

Tendo em vista o problema analisado e tendo como referência o uso das ferramentas de qualidade, foram priorizadas as ações corretivas e preventivas, descritas no plano de ação abaixo:

Figura 14: Quadro de Plano de ação - 5W2H.

Quadro de Plano de Ação - Ferramenta de Planejamento 5W2H

\begin{tabular}{|c|c|c|c|c|c|}
\hline Ação № & 1 & 2 & 3 & 4 & 5 \\
\hline $\begin{array}{l}\text { O que? } \\
\text { (What) }\end{array}$ & $\begin{array}{l}\text { Desenvolver sistema } \\
\text { de fixação sem } \\
\text { arrastador (sem } \\
\text { marcas na peça) }\end{array}$ & $\begin{array}{c}\text { Desenvolver calibre } \\
\text { para preset }\end{array}$ & $\begin{array}{l}\text { Desenvolver } \\
\text { Dispositivo de alarme } \\
\text { para alteração de } \\
\text { fechamento dos } \\
\text { rolos laminadores }\end{array}$ & $\begin{array}{c}\text { Aumentar o número } \\
\text { de inspeções visuais } \\
\text { nas peças }\end{array}$ & $\begin{array}{c}\text { Capacitação e } \\
\text { Treinamento } \\
\text { operacional }\end{array}$ \\
\hline $\begin{array}{l}\text { Quando? } \\
\text { (When) }\end{array}$ & $30 / 06 / 2014$ & $15 / 06 / 2014$ & $30 / 06 / 2014$ & $01 / 07 / / 2014$ & $01 / 07 / 20134$ \\
\hline $\begin{array}{l}\text { Onde? } \\
\text { (Where) }\end{array}$ & Linha de Produção & Linha de produção & Linha de produção & Linha de produção & Chão de fábrica \\
\hline $\begin{array}{l}\text { Quem? } \\
\text { (Who) }\end{array}$ & $\begin{array}{l}\text { Engenheiro de } \\
\text { processo }\end{array}$ & $\begin{array}{l}\text { Engenheiro de } \\
\text { Processo }\end{array}$ & $\begin{array}{l}\text { Engenheiro de } \\
\text { Processo }\end{array}$ & Gerente de qualidade & $\begin{array}{l}\text { Gerente industrial / } \\
\text { Gerente de qualidade }\end{array}$ \\
\hline $\begin{array}{l}\text { Por quê? } \\
\text { (Why) }\end{array}$ & $\begin{array}{l}\text { Marcas profunda } \\
\text { deixadas pelo } \\
\text { arrastador no } \\
\text { processo tornear }\end{array}$ & $\begin{array}{l}\text { Pressão excessiva para } \\
\text { laminar rosca. }\end{array}$ & $\begin{array}{l}\text { Alteração do ajuste } \\
\text { feito em set up. }\end{array}$ & $\begin{array}{l}\mathrm{N}^{\circ} \text { de inspeções } \\
\text { insuficiente }\end{array}$ & Falta de treinamento \\
\hline $\begin{array}{l}\text { Como? } \\
\text { (How) }\end{array}$ & $\begin{array}{l}\text { Pesquisa de processo } \\
\text { similar e Aquisição do } \\
\text { item via fornecedor } \\
\text { cadastrado. }\end{array}$ & $\begin{array}{c}\text { Simulação e } \\
\text { elaboração de } \\
\text { desenho técnico via } \\
\text { programa INVENTOR } \\
\text { para confecção do } \\
\text { dispositivo na } \\
\text { ferramentaria dentro } \\
\text { da empresa. }\end{array}$ & $\begin{array}{c}\text { Simulação e } \\
\text { elaboração de } \\
\text { desenho técnico via } \\
\text { programa INVENTOR } \\
\text { para confecção do } \\
\text { dispositivo na } \\
\text { ferramentaria dentro } \\
\text { da empresa. }\end{array}$ & $\begin{array}{c}\text { Alteração dos } \\
\text { procedimentos e } \\
\text { auditorias frequentes } \\
\text { nos processos. }\end{array}$ & $\begin{array}{c}\text { Realização de } \\
\text { Instruções de Trabalho } \\
\text { e treinamento com os } \\
\text { envolvidos na liderança } \\
\text { e nos processos } \\
\text { produtivos. }\end{array}$ \\
\hline $\begin{array}{c}\text { Quanto? } \\
\text { (How much) }\end{array}$ & $\mathrm{R} \$ 1.032,00$ & - & - & - & - \\
\hline
\end{tabular}

Fonte: Autores, (2014).

Para que o entendimento do nosso 5W2H fique claro em sua totalidade, estaremos detalhando e comentando cada ação dispostas na tabela acima

Ação $N^{o}$ 1: Desenvolvimento de um novo sistema de fixação da peça, que foi sem dúvida, uma das ações com maior relevância para solucionar o problema de trinca e batimento NC.

Figura 16: Novo dispositivo de fixação da peça.

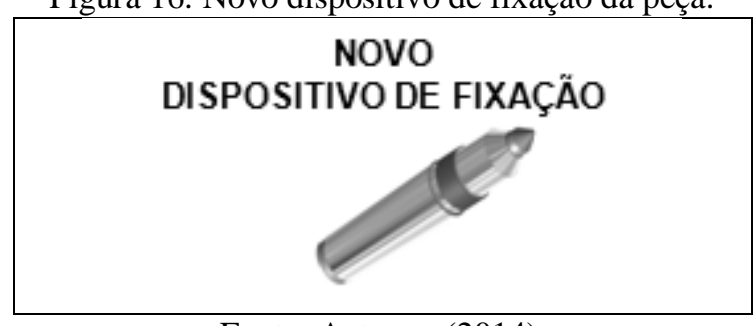

Fonte: Autores, (2014).

O novo sistema é autocentrante (ver figura 14), ou seja, busca o centro durante a usinagem da peça, e traz um ganho considerável em quesito de qualidade, pois como ele não possui pontas de arraste, com isso não deixa marcas profundas na peça. Sem as marcas profundas, ainda que haja esforço dos rolos no processo de laminação de rosca, não haverá trincas, eliminando completamente o problema de trinca e batimento $\mathrm{NC}$, visto que a peça possui uma melhor fixação durante a usinagem.

Ação $N^{o}$ 2: Desenvolver calibre para presset, buscando com isso a eliminação da pressão excessiva para laminação da rosca. $\mathrm{O}$ processo ganhou também produtividade com a redução do tempo com uma troca rápida de ferramenta e reduziu a sucata na troca de modelo e/ou ferramenta, pois a peça é produzida dentro das faixas de tolerâncias do desenho, faltando apenas alguns ajustes para o início da produção em massa.

Ação $\mathrm{N}^{\circ}$ 3: Desenvolver dispositivo de alarme para alteração de fechamento dos rolos laminadores, pois quando existe a necessidade de set-up (troca de modelo) os rolos laminadores são trocados e pode ocorrer esmagamento dos mesmos durante o seu fechamento, caso sua posição não estiver correta.

Ação $\mathrm{N}^{\circ}$ 4: Aumentar o número de inspeções visuais nas peças. Sabendo-se que inspeções não agregam valor ao produto e considerando que, não haverá aumento do tempo de processamento da peça, houve um aumento no número de inspeções visuais no processo. E importante lembrar que, nesta análise o fator qualidade é de suma importância para a empresa.

Ação $\mathrm{N}^{\circ}$ 5: Capacitação e Treinamento operacional. O treinamento e o desenvolvimento dos colaboradores envolvidos no processo são programas que geram um retorno certo para as organizações. Treinar significa tornar o colaborador hábil, capaz de entender e perceber e solucionar as falhas que possam ocorrer no processo.

Sendo implantadas as ações corretivas e preventivas proposta no $5 \mathrm{~W} 2 \mathrm{H}$, conforme nosso referencial teórico os custos de prevenção gerados foram considerados custos da qualidade, enquanto os custos de controle e de falhas foram considerados custos de má-qualidade. Portanto os treinamentos na produção é de grande relevância para que os recursos sejam aplicados para manutenção da qualidade evitando os gastos com a má qualidade, tendo em vista que são inversamente proporcionais. Isso significa que um investimento correto em custos de controle pode diminuir os custos das falhas dos controles e que o investimento exagerado nos custos das falhas pode provocar um aumento significativo na 
estrutura de custos da empresa, comprometendo sua estratégia competitiva.

Estudamos também que, quando o produto fornecido é produzido fora das especificações gera custos de falhas internas, onde para que esse produto venha atender as especificações do projeto são necessários serem feitos os retrabalhos, refugos e sucatas, é desperdiçado tempo provocado pelo problema de qualidade, além dos custos das perdas e sobras e Inspeção.

\section{Avaliação dos Impactos e Desbobramentos}

Observamos que a melhoria da Qualidade pode ser atribuída às suas raízes, como por exemplo, peças padronizadas e processo controlado diminuem as oportunidades de erro e muitas vezes, exigem menos mão de obra para sua produção e para os retrabalhos.

O trabalho mostrou a relação entre métodos e ferramentas, na gestão da qualidade de processos, num enfoque de integração teoria-prática. O uso das ferramentas de apoio tais como: brainstorming, diagrama de ishikawa, gráfico de pareto, $5 \mathrm{~W} 2 \mathrm{H} \mathrm{e}$ Matriz GUT se revelou de grande importância no trabalho para o processo de gestão da qualidade e desempenho.

Figura 15: Gráfico do índice de sucata 2014.

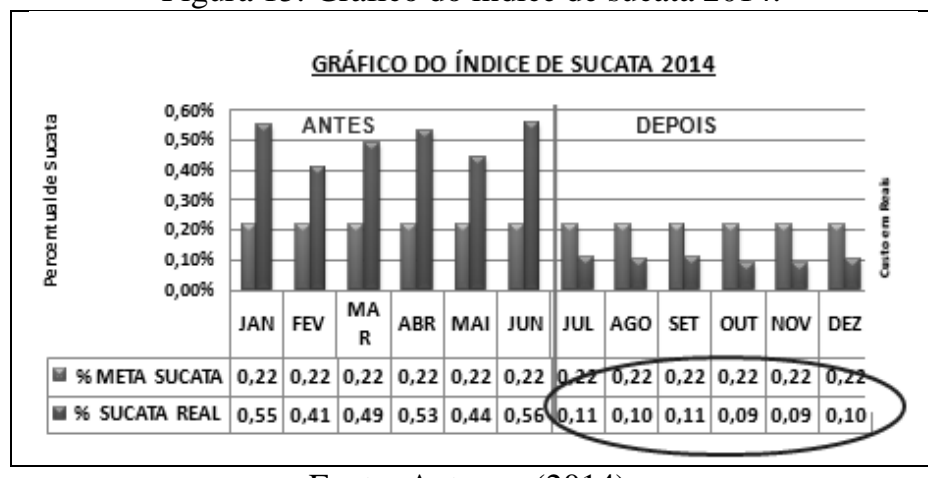

Fonte: Autores, (2014).

Nos meses após a implantação da melhoria, pode-se observar um ganho significativo na redução de sucata e índices totalmente dentro da meta da empresa (ver figura 15). A sucata da empresa que antes era mínimo de $0,41 \%$ passou para $0,09 \%$. Com um índice de $0,22 \%$ como meta isso se tornou excelente para a saúde financeira da empresa. Os colaboradores passaram a trabalhar mais confiantes e motivados, tendo em vista que o projeto na qual participaram e ainda participam surtiu resultados bastante satisfatórios.

As análises e propostas de solução de problemas feitas no $5 \mathrm{~W} 2 \mathrm{H}$ trouxeram determinado nível de maturidade, para que a empresa estudada mantenha e melhore os comportamentos que sustentam as habilidades já existentes em um contínuo processo de evolução da qualidade dos seus produtos.

Figura 16: Gráfico do Custo com sucata 2014.

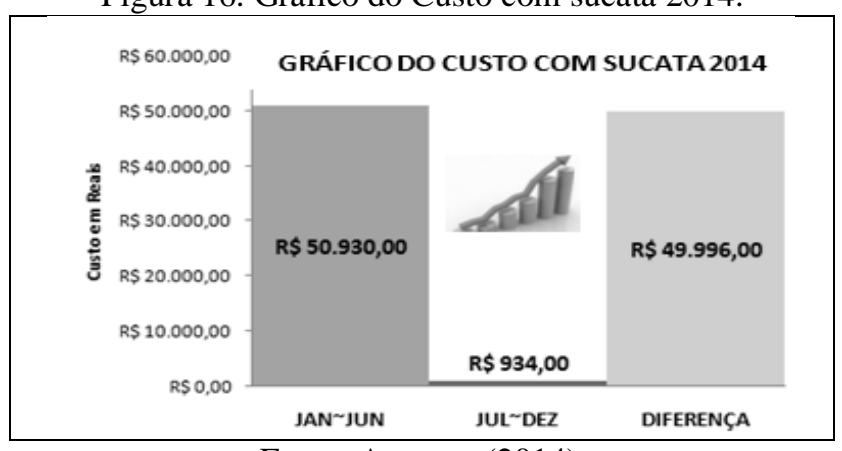

Fonte: Autores, (2014).
Como comprovado no estudo de caso apresentado acima, a empresa reduziu o percentual de defeitos com um ganho financeiro de $\mathrm{R} \$ 49.996,00$ ao ano, ou seja, o dinheiro deixou de ser desperdiçado com sucata em 2014 (ver figura 16).

Outros ganhos significativos que a empresa obteve foram:

1. Nos meses seguintes a implantação não houve registros de sucata por trinca/ batimento NC e o índice de sucata ficaram dentro da meta da empresa;

2. Como resultado da ação de melhoria, houve redução de desperdício para a empresa; figura 18).

3. Redução do tempo de set-up de 40 para 10 minutos (ver

4. Payback de investimento: 1 mês.

Figura 17: Gráfico do Tempo de Preparação.

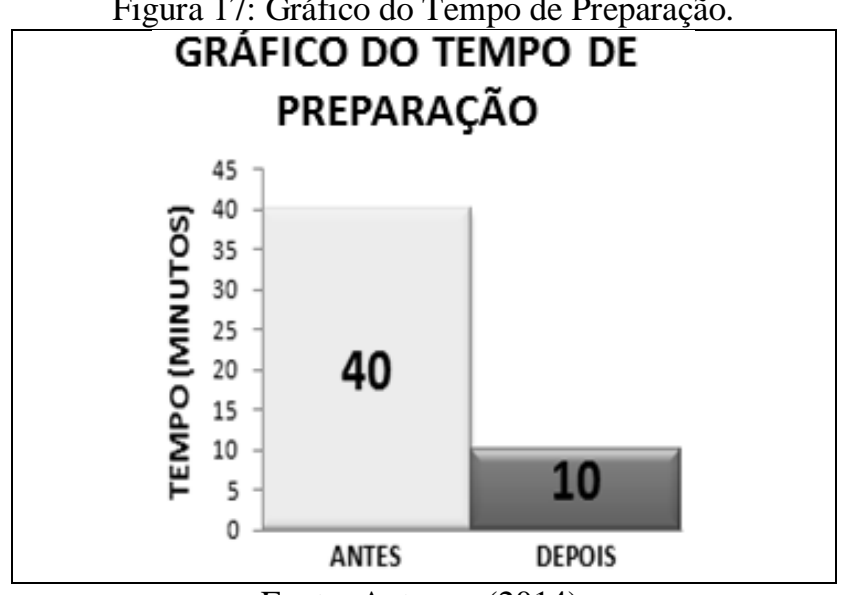

Fonte: Autores, (2014).

Um ganho significativo na produção foi em relação ao setup, que antes era de 40 minutos passou a ser de 10 minutos (ver figura 17). Isso foi possível devido aos novos métodos para troca rápida de ferramenta e calibre de presset destacados no plano de ação.

A melhoria também poderá ser estendida para todos os modelos de eixos, porém como todo sistema, deve-se monitorar a vida útil do novo dispositivo de fixação, ou seja, a cada 80.000 peças produzidas deverá realizar a troca do mesmo, a fim de garantir a conformidade dos produtos produzidos.

\section{CONCLUSÃO}

O trabalho mostrou a validade na adoção de ferramentas e métodos de gestão da qualidade em uma empresa metal mecânico, lotada no Pólo Industrial de Manaus no segmento de duas rodas. A empresa com perfil japonesa produz diversos produtos, dentre eles eixo de transmissão de moto. Produto escolhido para análise de problemas.

Através dos dados observados no trabalho, pode-se verificar que as ferramentas da qualidade adotadas no setor de usinagem, identificam e melhoram a qualidade dos produtos, serviços e processos através da utilização das chamadas metodologias da qualidade, que têm a finalidade de eliminar ou reduzir as variações e manter estáveis os processos, através da descrição e priorização dos problemas, identificação das possíveis causas e daí as causas básicas dos problemas, bem como o desenvolvimento e implementação de soluções efetivas para os problemas.

O setor analisado na empresa era a usinagem de eixo de transmissão, o motivo da escolha surgiu devido o alto índice de sucata no setor, encontrados nos indicadores da empresa, onde todos os processos internos da empresa são analisados para facilitar 
as análises dos problemas. A meta do índice de sucata da empresa que é de $0,20 \%$, estava no real com no mínimo de $0,41 \%$ e máximo de $0,56 \%$ de sucata, gerando um elevado custo com desperdício. $\mathrm{O}$ objetivo então era reduzir índice de sucata em $40 \%$ do eixo de transmissão no setor de usinagem. Analisando a causa do problema com uso das ferramentas da qualidade, tais como Diagrama de Pareto, Diagrama de Ishikawa e Matriz GUT, o grupo chegou a conclusão que o problema, que representava $83 \%$ do índice de sucata estava relacionado ao dispositivo de fixação da peça, que era utilizada no processo de torneamento dos diâmetros. O dispositivo que era inadequado para o processo estava originando problemas de TRINCA e BATIMENTO NÃO CONFORME nas peças, o mesmo possuía pontas de arraste, deixando marcas profundas na peça e com o esforço do processo posterior trincava a peça, devido a área está fragilizada.

Os resultados das ações surtiram efeitos positivos e surpreendente, pois no mês seguinte pode-se observar uma redução significativa no índice de sucata, já com os indicadores dentro da meta da empresa. $\mathrm{O}$ setor conseguiu um índice de $0,11 \%$ de sucata e assim manteve-se até final deste trabalho, sendo que a meta é de $0,22 \%$. O tempo de setup também foi reduzido de 40 minutos para 10minutos com a mudança no método de troca rápida de ferramenta. Um ganho em produtividade, visto que houve redução no desperdício de material, tempo, ferramentas e mão de obra.

Portanto, acredita-se que esse modelo pode servir de guia para a boa gestão de competências, visando à melhoria contínua dos sistemas de gestão da qualidade, pois é possível considerar aspectos técnicos e metodológicos juntamente com aspectos abstratos, estratificando-os de acordo a detectar os pontos críticos ou gargalos do sistema produtivo da empresa. Porém, cabe a cada empresa investir em tecnologias e treinamentos operacionais para que o uso desse um modelo possa se tornar uma rotina enraizada em sua cultura. Dessa forma, um aprendizado que ficaria impregnado na cultura organizacional e permitiria a passagem pelos níveis de maturidade da melhoria contínua.

\section{REFERÊNCIAS}

[1] Cerqueira Neto, E. P. Gestão da qualidade: princípios e métodos. 3 ed. São Paulo: Pioneira, 1993.

[2] Chiavenato, Idalberto. Administração nos novos tempos. 2. ed. Rio de Janeiro: Campus, 1999.

[3] Crosby, P. B. Qualidade é Investimento. Tradução de Áurea Weisenberg. Rio de Janeiro: José Olympio, 1992.

[4] Gitlow, Howard S. Planejando a qualidade, a produtividade e a competitividade. Tradução de Mauro Paganotti. Rio de Janeiro: Qualitymark, 1993.

[5] Gaither, Norman; Frazier, Greg. Administração da produção e operações. 8. ed. São Paulo: Pioneira, 2001.

[6] Juran, J. M.; Gryna, F. M. Controle da qualidade handbook conceitos, políticas e filosofia da qualidade. 4. ed. Makron Books McGraw-Hill, v.1. São Paulo, 1999.

[7] Juran, Joseph M. Juran planejando para a qualidade. São Paulo: Pioneira, 1990.

[8] Lakatos, E. M.; Marconi, M. de A. Fundamentos de metodologia científica. 3. ed. São Paulo: Atlas, 1996.
[9] LUFT, C. P. Minidicionário da Língua Portuguesa. 19ª ed. São Paulo: ÁTICA, 2002.

[10] Manãs, A. V. Inovação e Competitividade: um enfoque na qualidade. In: Oliveira, Otávio J.(Org.). Gestão da qualidade: tópicos avançados. São Paulo: Pioneira Thomson Learning, 2004.

[11] Paladini, E. P. Gestão da qualidade no processo: a qualidade na produção de bens e serviços. São Paulo: Atlas, 1995.

[12] Oakland, J. S. Gerenciamento da qualidade total. São Paulo: Nobel, 1994.

[13] Oliveira, O. J. (Org.). Gestão da qualidade: tópicos avançados. São Paulo: Pioneira Thomson Learning, 2004.

[14] Werkema. M. C. C. Ferramentas estatísticas básicas para o gerenciamento de processos. Belo Horizonte: Fundação Cristiano Ottoni, 2006. 